\title{
Interculturalidade crítica e educação popular em diálogo
}

\section{Critical interculturalism and popular education in dialogue}

\section{Interculturalidad crítica y educación popular em diálogo}

\author{
José Wnilson Figueiredo' \\ Instituto Federal Catarinense - Campus de Concórdia, Professor de Matemática \\ Walter Frantz ${ }^{2}$
}

Universidade Regional do Noroeste do Estado do Rio Grande do Sul, Professor do Programa de Pós-graduação em Educação nas Ciências; Integrante do Grupo de Estudos de Educação Popular (GEEP), movimentos e organizações sociais

Resumo: No artigo em questão apresentam-se reflexões acerca da relevância da educação popular, propugnada por Paulo Freire, com vistas à abertura de sendas possíveis para a instauração da interculturalidade crítica no mundo das escolas e demais organizações sociais. Para tanto, apoiamo-nos nas categorias da ética do reconhecimento e do diálogo intercultural, presentes nas obras desse autor, como princípios fundantes para a emergência e a efetivação de processos político-pedagógicos. Engendrados em relações interhumanas, acreditamos ser possível, a partir da denúncia do colonialismo e da colonialidade do ser, dos saberes e do poder, o anúncio de uma educação intercultural crítica, forjada na igualdade associada ao respeito às diferenças de classe, etnia, sexo, gênero, nacionalidade, língua e religião existentes entre as pessoas.

Palavras-chave: Educação intercultural. Concepção freireana. Diversidade cultural.

\begin{abstract}
This article presents reflections on the relevance of popular education, advocated by Paulo Freire, with a view to opening prospects for the establishment of critical interculturalism in schools and other social organizations. Therefore, we take as reference the categories of ethics of

Doutor em Educação nas Ciências pela Universidade Regional do Noroeste do Estado do Rio Grande do Sul; Mestre em Modelagem Matemática pela Universidade Regional do Noroeste do Estado do Rio Grande do Sul.

2 Doutor em Ciências Educativas; Especialista em Economia da Cooperação pela University of Münster.
\end{abstract}


the acceptance and the intercultural dialogue - contained in the works of this author. These are foundational principles for the emergency and the effectiveness of political and pedagogical processes engendered in interhuman relationships, which allow - from denunciation of colonialism and coloniality of being, knowledge and power colonizing - the announcement of an intercultural critical education, in equality forged and associated with respect to differences of class, ethnicity, sex, gender, nationality, language and religion that exist between people.

Keywords: Intercultural education. Freire's conception. Cultural diversity.

Resumen: El presente artículo presenta reflexiones sobre la relevancia de la educación popular propugnada por Paulo Freire, con vistas a la abertura de sendas posibles para la instauración de la interculturalidad crítica, en el mundo de las escuelas y demás organizaciones sociales. Para eso, nos apoyamos en las categorías de la ética del reconocimiento del diálogo intercultural, presentes en las obras de ese autor, como principios basilares para la emergencia y la efectuación de procesos políticos pedagógicos. Engendrados en relaciones interhumanas, creemos ser posible, a partir de la denuncia del colonialismo y de la colonialidad del ser, de los saberes y del poder, el anuncio de una educación intercultural crítica, forjada en la igualdad asociada al respecto a las diferencias de clase, etnia, género, nacionalidad, lengua y religión existentes entre las personas.

Palabras clave: Educación intercultural. Concepción freireana. Diversidad intercultural.

\section{INTRODUÇÃO}

Este texto compreende um exercício de reflexão, tendo o pensamento de Paulo Freire como "fio condutor" do processo de interlocução que se busca estabelecer com diferentes autores, objetivando identificar uma relação entre interculturalidade crítica e educação popular.

Nos subsistemas e sistemas do mundo globalizado, prevalece um discurso e uma prática hegemônica do multiculturalismo apoiados no 
"reconhecimento" das diferenças existentes entre os seres humanos nas mais diferentes dimensões constituintes da vida sem considerar as desigualdades acarretadas por essas diferenças, ou seja, as práticas sociais arraigadas no multiculturalismo reconhecem que há diferenças, por exemplo, entre brancos e negros, porém mencionam a disparidade de oportunidades sociais em favor dos brancos em nossas sociedades atuais quando comparadas àquelas postas à disposição dos negros.

Portanto, o multiculturalismo acaba se associando ao discurso da ética neoliberal de mercado, o qual também reconhece a desigualdade e a injustiça social e, ao mesmo tempo, não promove ações a respeito de projetos que levem a uma mudança substantiva em termos de uma produção da igualdade em meio à diversidade cultural.

Dessa feita, o multiculturalismo adota e busca uma integração de todas as culturas desde que, por exemplo, culturas diferentes - como é o caso dos imigrantes - se submetam e aceitem os costumes e os hábitos das sociedades majoritárias. De modo contrário, o interculturalismo crítico pressupõe a luta pela igualdade de todos os povos em meio ao reconhecimento de suas diferenças culturais, as quais são evidenciadas e promovidas a partir do encontro dos diversos saberes de todos os povos, isto é, não há cultura superior, mas culturas diversas no mundo que se completam em suas diferentes caminhadas históricas.

Nesse caminho, um projeto político fundado em uma educação centrada na interculturalidade crítica tem como ponto de partida e de chegada a emersão de sujeitos subalternos por meio da denúncia de situações de invisibilidade social e cultural desses sujeitos, especialmente os que vivem no Sul global e também as populações minoritárias do Norte global, proporcionadas pelo multiculturalismo de corte neoliberal.

Esse projeto se realiza mediante essa denúncia concomitante ao anúncio e à efetivação de um agir calcado em um diálogo autêntico, em que se estabelecem relações intersubjetivas pautadas na superação do colonialismo e da colonialidade, cujo objetivo é a superação das iniquidades culturais, 
políticas, sociais e econômicas e, consequentemente, a constituição de um mundo ancorado na cooperação.

Assim, a interculturalidade crítica se associa em termos éticos, políticos e epistemológicos à educação popular, pois essa modalidade de educação traduz um caminho, um processo pedagógico, de "constituição de sujeitos críticos" de sua herança cultural e práticas de vida, de sua leitura de mundo. Tem suas raízes históricas na luta pela superação da opressão, manipulação e dominação.

Enfim, a educação popular e a interculturalidade crítica convergem em virtude do fato de que comungam de um mesmo ideal de transformação social, protagonizado pelo povo e pelos intelectuais comprometidos com um mundo diferente, o qual é estruturado no diálogo de saberes em prol da (re) construção de relações amparadas na dádiva, a qual se define por atos e gestos amparados na tríade do dar, do receber e do retribuir os bens materiais e os bens simbólicos da vida, em oposição à competitividade voraz hegemônica do mundo contemporâneo. Assim, a dádiva é portadora de princípios ligados à reciprocidade que se opõem ao modo de vida individualista, que se caracteriza pela não abertura ao outro.

Trata-se de um texto que decorre de leituras e reflexões, isto é, em diálogo com autores que se ocupam, especialmente, com a problemática da interculturalidade e da educação popular, com referência a aspectos da história do colonialismo europeu, tendo como "pano de fundo", especialmente a América Latina, um continente multicultural. Nessa direção, a abordagem metodológica empregada foi de cunho qualitativo por intermédio da leitura e da interpretação da conjuntura política, econômica, social, cultural e educacional do mundo atual, cujo ponto de apoio foi o estabelecimento do diálogo entre os diversos autores vinculados a vivências comprometidas com processos políticopedagógicos sustentados em uma ética em que todas as pessoas caibam no mundo.

Para tanto, adotou-se um olhar - ainda que provisório - acerca da realidade das nossas sociedades, no que diz respeito aos acontecimentos e às vivências que ocorrem entre os sujeitos dessas sociedades, ou seja, esse olhar 
busca entender e veicular essencialmente a percepção do que acontece em nossas sociedades no atual cenário da contemporaneidade.

Embora o texto não decorra de dados empíricos de campo, não se pode desconsiderar que as reflexões têm suas raízes e suporte em contextos históricos, embora apenas referenciados em amplos traços.

Pensamentos e reflexões são expressões de vivências e experiências de um cotidiano do "campo empírico da vida", isto é, daquilo que, comumente, denominamos realidade. No entanto, não existe leitura crítica de uma realidade sem uma referência ou interlocução teórica. A leitura crítica de um cotidiano de vida ocorre no diálogo dos sujeitos das experiências múltiplas, orientados pela interlocução entre si à luz de um campo teórico. Esse é um dos princípios fundamentais da pesquisa. Afirma Marques (1998, p. 102) que "pesquisar é puxar os cordões que ligam entre si as práticas de um mesmo campo empírico em sua continuidade histórica e, ao mesmo compasso, os entrelaçam com os cordões que vinculam e conduzem os entendimentos que de tais práticas se alcançam no campo teórico." Portanto, puxemos alguns cordões da história.

Na conjuntura atual, vive-se sob o império hegemônico da cosmovisão da dominação, que se imiscui nos aspectos sociais, políticos, econômicos, culturais e educacionais dos espaços escolares e dos demais espaços das sociedades, colonizando-os a partir da veiculação de valores ancorados no ideário da lógica capitalística da globalização. Para além de seus aspectos econômicos, essa lógica se espalha por todos os continentes, caracterizada pela imposição da monocultura do ser, do saber e do poder, promovida pelas nações do Norte global à custa do ocultamento dos saberes, do ser e dos poderes das populações dos países do Sul global.

No caso latino-americano especificamente, essa cosmovisão da dominação remonta à invasão e à dominação da América pelos europeus, em 1492, integrando-se os novos territórios e populações autóctones ao contexto de uma economia de busca e exploração de riquezas. A colonização dos novos territórios precisa ser compreendida a partir de interesses econômicos europeus em expansão que, no entanto, traz consigo questões de ordem cultural e 
política. No processo da Conquista, constitui-se e se afirma um pensamento único eurocentrista (WALLERSTEIN, 2007), de cunho discriminatório, que é transmitido por meio de uma política e de uma pedagogia que promovem uma divisão do mundo em duas regiões, por meio do estabelecimento de linhas cartográficas, demarcadoras dessa divisão, impostas no passado colonial, mas que persistem até os dias atuais como um sistema de interesses e poder (SANTOS, 2005). Afirma Wallerstein (2007, p. 29) que: "A história do sistemamundo moderno tem sido, em grande parte, a história da expansão dos povos e dos Estados europeus pelo resto do mundo." E a coluna vertebral dessa expansão foram os seus interesses econômicos em expansão (HUBERMAN, 1982).

Essas linhas cartográficas são estabelecidas com base no critério aportado no pensamento da modernidade eurocêntrica, que distingue as regiões do mundo a partir de uma classificação fundada na visibilidade de apenas uma minoria da população mundial, a qual ocupa uma pequena fração do Planeta, em detrimento da maioria da população situada em uma extensão territorial maior do que o território ocupado por aquela minoria.

Dessa forma, a visibilidade é conseguida e é mantida pela exclusão, violência e opressão de natureza epistemológica, política, social e cultural decorrentes do colonialismo e da colonialidade, que separam a realidade da vida das sociedades em universos distintos, de acordo com a região geográfica e a etnia. Assim, pessoas que pertencem às etnias e às regiões supostamente consideradas desenvolvidas pelo padrão eurocêntrico encobrem aquelas pertencentes às etnias e às regiões diversas desse padrão estabelecido. Esse padrão é balizado pela racionalidade técnica instrumental hegemônica, a qual se baseia na premissa da discriminação e da naturalização das diferenças evidenciadas na assertiva de que as populações dos Estados Unidos e da Europa são as que possuem os saberes verdadeiros, as etnias e as manifestações culturais superiores, enquanto os saberes, as etnias e as manifestações culturais dos povos provenientes da América Latina, Ásia e África são considerados atrasados do ponto de vista filosófico e científico apregoado por essa racionalidade (DUSSEL, 1993; MIGNOLO, 2005; QUIJANO, 2007; SANTOS, 2010). 
Essa racionalidade técnica instrumental coloniza o imaginário das pessoas ao impor prerrogativas provenientes do ideário do paradigma da modernidade eurocêntrica relacionadas à valorização de aspectos a serem seguidos na vida social, como o individualismo, o dinheiro como medida de todas as coisas, o crescimento e o progresso infinito, o antropocentrismo, o patriarcado, a busca do lucro a qualquer custo, a competitividade, o racismo epistêmico, o consumismo e a apropriação e a dominação da natureza.

Como consequência do triunfo dessa racionalidade, intensifica-se a desumanização pela ausência de valores atinentes à promoção da dignidade das pessoas no que diz respeito à solidariedade e à cooperação entre os seres humanos e entre estes e a natureza. Trata-se de valores como a dádiva, o amor e a amizade, o cuidado e a responsabilidade com as gerações presentes e as gerações vindouras, o consumo parcimonioso e responsável, o crescimento com base na ideia de uma abundância frugal e a busca da igualdade de todas as pessoas do mundo com base no respeito às diferenças de classe, nacionalidade, etnia, sexo, gênero, religião e língua.

Com efeito, entretanto, esse aumento da desumanização tem provocado atitudes contestatórias em oposição a essa racionalidade, que oprime e exclui a maioria da população mundial a partir da ideia de centralidade e superioridade do Norte global. Porém, têm emergido movimentos de resistência ao eurocentrismo em proporção mundial, especialmente nas nações do Sul global, em torno do anúncio e da implantação de possibilidades assentadas em políticas públicas capazes de vislumbrar novos caminhos que substituam a despersonalização vigente pela perspectiva da educação promotora da personalização na vida social nas escalas local, nacional e global. Nessa perspectiva, essa educação:

Não pode ser concebida apenas como um processo institucional, seu lado visível, mas fundamentalmente, como um investimento formativo do humano, seja no âmbito da relação social coletiva. As intervenções educacionais, mediadoras e insubstituíveis da formação humana, ancoram-se na condição da educabilidade do homem. $\bigcirc$ que está em pauta não é só a habilitação técnica, mas uma autêntica bildung, a formação de uma personalidade integral, o investimento sistemático e intencionalizado na construção 
do humano no homem, sua humanização, sua personalização. (SEVERINO, 2009, p. 160).

Desse modo, essa personalização proclama em favor de relações humanas forjadas em práticas fundadas na solidariedade - no, com e pelo mundo - como forma de se construir a ética universal do ser humano, forjada na abertura e na disponibilidade recíprocas entre as pessoas, estabelecidas por meio de relações intersubjetivas com base na dádiva sem medida em oposição à hegemonia da ética do mercado, fundamentada na competitividade e no lucro (FREIRE, 1996; MOUNIER, 2004). Ética de mercado que se configura por relacionamentos verticais fundados na opressão e na dominação, por parte dos detentores do poder em prejuízo daqueles que são subalternizados. De acordo com Bucci e Kehl (2004, p. 22): "O capital é o sujeito que sujeita a todos os outros. [...] Os indivíduos são sujeitos inconscientes do capital."

Ao contrário, a personalização é edificada por intermédio de um movimento de transmutação dos indivíduos em pessoas, o que acontece pela "saída" desses indivíduos em direção aos outros e à comunidade da vida, a partir da assunção do diálogo e da ética da alteridade. A interculturalidade crítica nasce da atuação dos seres humanos em comunhão, com vistas ao crescimento de todos e da comunidade da vida, tendo como horizonte a busca da igualdade de todos, em meio ao respeito à diversidade cultural.

Esse crescimento é realizado com base em encontros dialógicos estruturados no cuidado e na responsabilidade com a vida, a qual é construída sob a égide do imperativo da vocação ontológica e histórica dos seres humanos em ser mais, em conjunto com os outros, associado à preservação da natureza (BOFF, 2000; BUBER, 2001; FREIRE, 2005).

Esses encontros ocorrem pela disponibilidade, caracterizada pelo rompimento do individualismo, do narcisismo e do egocentrismo, concomitantemente com a tomada de posição em favor da realização do reino do entre forjado em relações ancoradas no princípio buberiano do "Eu-Tu", o qual se estrutura pela amizade e congraçamento mútuo entre os pares desses relacionamentos, os quais ensinam e aprendem cooperativa e solidariamente (FREIRE, 1996; BUBER, 2001; MOUNIER, 2004). Esse reino é pautado pelo 
encontro genuíno entre as pessoas, em que a essência desse encontro é o princípio dialógico marcado pelo reconhecimento do outro como sujeito e pela não reificação das pessoas, ou seja, os polos desse encontro comungam e compartilham os mesmos sonhos e ideais visando à assunção de um mundo erigido pela solidariedade e pela justiça social.

Nesse sentido, as categorias da ética do reconhecimento do outro e do diálogo intercultural, presentes nas obras de Freire, podem proporcionar um novo horizonte para a construção de uma educação intercultural crítica no mundo. Essa possibilidade educativa pode se constituir por meio da intercomunicação entre o construto teórico e prático da educação freireana e os saberes oriundos de governos de matiz popular, movimentos e organizações sociais originários do Sul global que, em convergência com movimentos de educação popular do Norte global, podem mobilizar práticas sociais que catalisem e promovam a superação da situação de colonialidade, a qual se caracteriza pela:

expoliação colonial legitimada por um imaginário que estabelece diferenças incomensuráveis entre o colonizador e o colonizado. As noções de "raça" e de "cultura" operam aqui como um dispositivo taxonômico que gera identidades opostas. $\bigcirc$ colonizado aparece como o "outro da razão". O qual justifica um poder disciplinador por parte do colonizador. A maldade, a barbárie e a incontinência são marcas "identitárias" do colonizado, enquanto que a bondade, a civilização e a racionalidade são próprias do colonizador. (CASTRO-GÓMEZ, 2005, p. 177-178).

Essa transformação poderá vir a ser concretizada das mais diversas formas a partir da denúncia do contexto histórico e sociocultural marcado pelo colonialismo e pela colonialidade em que a humanidade ainda está imersa no presente. A tomada de consciência dessa situação, por intermédio de uma práxis entendida como ação e reflexão, permite uma análise mediante a qual podem ser anunciadas ações no, com e pelo mundo, em torno da elaboração de saberes relacionados a uma epistemologia, uma política e uma pedagogia com o objetivo de proporcionar processos de ensino e aprendizagem assentados no interculturalismo crítico. Esses processos serão consignados por meio da 
busca da igualdade pela via do reconhecimento do outro em suas diferenças, acolhido na sua totalidade como pessoa e, consequentemente, que não seja negado como ser humano, isto é, subsumido, tornado coisa, oprimido, sujeitado e violentado (DUSSEL, 1993).

Enfim, neste artigo, buscamos refletir sobre o papel da educação intercultural, aportada pelo ideário freireano, visando a uma utopia concreta de convivialidade humana a partir das escolas, governos populares - como é o caso dos governos em vigor de Portugal, Uruguai e Bolívia e, em um passado recente, dos governos Dilma e Lula no Brasil - e intelectuais críticos, como é o caso, para citar três exemplos, de Boaventura de Sousa Santos, Enrique Dussel, Leonardo Boff e tantos outros pensadores, que vivem e lutam por um mundo mais humano e solidário, e demais organizações, que podemos citar: movimentos de camponeses e movimento dos sem-teto no Brasil, projeto Alice da Universidade de Coimbra em Portugal e demais movimentos espalhados pelo mundo que reagem e resistem à lógica e ética capitalística, cujo objetivo é o lucro sem limites à custa da exploração colonialista e da colonialidade.

Essa convivialidade propõe um viver voltado para a responsabilidade com os outros e a natureza, em que o conflito em vez de ser negado é potencializado a partir de um diálogo e da cooperação constante entre todos os seres humanos para que toda a humanidade possa usufruir de uma vida sem opressão, ou seja, a convivialidade propõe um conviver com base na assertiva de que todos sejam incluídos nos aspectos sociais, políticos, econômicos e culturais do mundo humano.

Acreditamos que a criticidade, as reações e resistências podem anunciar e promover experiências político-pedagógicas em razão de um ensinar e de um aprender dirigidos para a consecução de uma vida em comunhão em meio ao respeito à diversidade cultural de todos os seres humanos. 


\section{DO COLONIALISMO À COLONIADADE: DESAFIOS À SUPERAÇÃO}

Os acontecimentos sociais e culturais, ao longo da história da humanidade, evidenciam que, em linhas gerais, os encontros de povos de culturas diferentes ocasionaram - quase sempre - a opressão e a dominação por parte dos povos de maior poder bélico e econômico sobre aqueles que não dispunham desse poder. Como consequência, historicamente, esses povos foram e são esmagados do ponto de vista social, político e cultural na sua maneira de expressar os seus saberes, os seus conhecimentos, a sua maneira de ser e de compreender o mundo e o seu modo de imaginar e exercer o poder (WALLERSTEIN, 2007).

Um exemplo histórico clássico da dominação de uma cultura sobre a outra é a Conquista da América. Impôs-se o modo de ser dos povos europeus pela violência física e pela violência simbólica praticada, quando da invasão e do apossamento do território, pela colonização do imaginário desses povos por meio da transmissão de ideias adstritas aos filósofos europeus, em que Hegel foi um representante importante na veiculação dessas ideias, as quais afirmavam que os hábitos, os saberes, os conhecimentos e os valores dos europeus eram superiores e, por esse motivo, deveriam ser assimilados pelos povos subjugados ao imperativo do eurocentrismo.

Essa cosmovisão de Hegel, que fundamenta a "suposta superioridade europeia" em relação aos outros povos, fundamenta-se nas teses da exclusão e do determinismo geográfico.

A partir dos fundamentos naturais por ele definidos, o cenário em que se poderia realizar a história universal seria necessariamente o Norte e o "centro". Decretada a irrelevância da América do Sul para a história, Hegel reserva páginas de uma retórica altamente elogiosa à América do Norte como cenário futuro da História Universal. (ANDREOLA, 2002, p. 123-124).

Portanto, por essa visão de Hegel, as populações dos territórios conquistados, diferentes das populações da Europa, eram consideradas 
inferiores em todos os aspectos, ou seja, o "outro" não era tolerado no seu modo de ser. Dessa forma, essa visão "abria a porta" e dava sustentação para a consecução de atos imperialistas de dominação dos europeus aos povos da América, a qual se desenhava pela submissão do outro (os indígenas) por intermédio de uma violência etnocêntrica, mediante a utilização de métodos inerentes ao colonialismo e à colonialidade do ser, dos saberes e do poder, efetuada contra os povos nativos do continente americano.

Esse colonialismo e essa colonialidade destruíram, física e simbolicamente, o ser e as manifestações culturais dessas populações, produzindo um genocídio e um epistemicídio por ocasião da invasão e da dominação da América pelos europeus.

Apesar de o colonialismo na sua forma política clássica ter desaparecido com a independência dos países que estiveram sob o jugo dos países europeus, o colonialismo persiste nos dias atuais sob a forma de colonialidade. Esta impõe o modo de ser europeu pela veiculação de informações por meio dos sistemas constitutivos hegemônicos das sociedades do Sul global, como escolas, governos e meios de comunicação de massa, que repassam a ideologia advinda do Norte global como a mais desenvolvida em termos da produção de conhecimentos da Filosofia e da Ciência em relação ao que é produzido no Sul global.

A respeito desse fenômeno da colonialidade, Oliveira e Candau (2010, p. 17) expressam que: "modernidade e colonialidade são as duas faces da mesma moeda. Graças à colonialidade, a Europa pode produzir as Ciências humanas como modelo único, universal e objetivo na produção de conhecimentos, além de deserdar todas as epistemologias da periferia do ocidente."

colonialismo e a colonialidade são duas expressões do domínio colonial imposto pelo eurocentrismo, porém apresentam diferenças nas suas metodologias de atuação. $\bigcirc$ colonialismo representa a forma de dominação em que determinado país detém o poder político, administrativo, econômico, militar e cultural sobre determinado território que está subordinado a esse país, como foi o caso dos países africanos que estiveram até a década de 1970 sob 
a tutela de Portugal. Por sua vez, a colonialidade é uma forma de colonização que, apesar de advir do colonialismo, difere deste pela natureza da sua abrangência em razão de que a colonialidade não se restringe à relação opressão-subjugação existente entre uma nação que oprime e a outra que é oprimida. Essa colonialidade é introjetada em todas as instâncias da vida do povo colonizado, fazendo com que este hospede a cultura do colonizador e passe a assimilar essa cultura como se fosse a sua própria cultura.

O colonialismo denota uma relação política e econômica, na qual a soberania de um povo está no poder de outro povo ou nação, o que constitui a referida nação em império. Diferente desta ideia, a colonialidade se refere a um padrão de poder que emergiu como resultado do colonialismo moderno, mas em vez de estar limitado a uma relação formal de poder entre dois povos ou nações, se relaciona à forma como o trabalho, o conhecimento, a autoridade e as relações intersubjetivas se articulam entre si através do mercado capitalista mundial e da ideia de raça. Assim, apesar do colonialismo preceder a colonialidade, a colonialidade sobrevive ao colonialismo. Ela se mantém viva em textos didáticos, nos critérios para um bom trabalho acadêmico, na cultura, no sentido comum, na autoimagem dos povos, nas aspirações dos sujeitos e em muitos outros aspectos de nossa experiência moderna. Neste sentido, respiramos a colonialidade na modernidade cotidianamente. (TORRES, 2007, p. 131).

Assim, apesar de estarmos envolvidos por uma multiplicidade de culturas, vivemos sob o signo da marginalização e da segregação social em diversos aspectos, como, por exemplo, etnia, gênero, nacionalidade, língua, religião, sexo e classe social, no que diz respeito à intolerância dos povos do Norte global (países ricos) aos povos do Sul global (países pobres que majoritariamente estão ao sul da Europa e dos Estados Unidos), os quais proclamam valores e identidades culturais diversas daquelas consideradas como "credíveis" pelos corolários do paradigma da modernidade eurocêntrica.

Em decorrência dessa intolerância, incrusta-se a violência pelo fato de que somente alguns têm direito a vez e voz (os colonizadores), ao passo que os outros (os colonizados) são condenados ao silêncio pela sujeição de suas subjetividades. Dessa maneira, os colonizadores tornam os colonizados 
objetos ao explorá-los, moldando, assim, os seus pensamentos e a sua maneira de atuarem no mundo (GUATTARI; ROLNIK, 2000).

A respeito dessa violência, Fanon (1968, p. 26) expressa que: "a exploração do colonizado pelo colono foi levada a cabo com grande reforço de baionetas e canhões. $\bigcirc$ colono e o colonizado são velhos conhecidos. E de fato, o colono tem razão quando diz que os conhece. É o colono que fez e continua a fazer o colonizado." Quanto à relação de poder colonizador-colonizado, observa-se que:

$\bigcirc$ mundo colonial é um mundo maniqueísta. Não basta ao colonizador limitar fisicamente o colonizado, com suas polícias e seus exércitos, o espaço do colonizado. Assim para ilustrar o caráter totalitário da exploração colonial, o colonizador faz do colonizado uma quinta essência do mal. A sociedade colonizada não somente se define como uma sociedade sem valores [...] $\bigcirc$ indígena é declarado impermeável à ética, aos valores. É, e atrevemos a dizer, o inimigo dos valores. Neste sentido, é um mal absoluto. Elemento corrosivo de tudo o que o cerca, elemento deformador, capaz de desfigurar tudo o que se refere à estética ou à moral, depositário de forças maléficas. (FANON, 2003, p. 35-36).

Logo, o colonialismo impede que os oprimidos - os colonizados - pensem e atuem por si mesmos, pois para estes são destinados apenas os papéis secundários na vida social. $\bigcirc$ que resta, portanto, para os colonizados é pensar e agir de acordo com as prescrições sugeridas pelos colonizadores, os quais sufocam o sonho daqueles subalternizados.

Uma vez que suporta a colonização, a única alternativa para o colonizado é a assimilação ou a petrificação. Sendo-lhe recusada a assimilação, nós o veremos nada mais lhe resta senão viver fora do tempo. É levado a isso pela colonização, e em certa medida, acomoda-se. A projeção e a construção de um futuro sendo-lhe proibidas, e limita-se a um presente; e esse presente, ele mesmo, é amputado, abstrato. (MEMMI, 1977, p. 94). 
Caminhando na mesma direção das sendas apontadas por Fanon (1968) e Memmi (1977), verificamos que o império das ideias centradas na colonização e na colonialiade impede - na maioria dos espaços sociais - a efetivação de uma educação intercultural crítica.

\section{RUMO À EDUCAÇÃO INTERCULTURAL CRÍTICA: UM LUGAR À EDUCAÇÃO POPULAR}

Em meio à riqueza da pluralidade de culturas existentes no mundo, o tema da educação intercultural é de enorme importância para a edificação de sociedades constituídas por práticas pedagógicas engendradas em valores que não apenas respeitem a diversidade cultural, mas também que a valorizem em todos os campos de atuação da vida social.

Pelo fato de sermos seres de culturas, nós - os seres humanos - nos descentramos e vamos ao encontro dos outros no sentido de estabelecermos interações promotoras de aprendizagens capazes de possibilitarem a criação e a recriação de processos políticos e pedagógicos que produzam a mudança nas pessoas e na natureza. Dessa maneira, essa marca da cultura é o que nos distingue como humanos em comparação aos animais, já que pela nossa intervenção modificamos o mundo, em sua totalidade, por intermédio de ações realizadas a partir do nosso contato com toda a comunidade da vida, que é constituída pelos seres humanos e pela vida extra-humana (os outros seres vivos). Já, diferente dos humanos, os animais não transformam o mundo; apenas se adaptam a este.

Como consequência disso, os seres humanos aprendem, ao longo da vida, pela invenção e reinvenção de suas atividades. Por outro lado, os animais são seres que não criam e recriam suas experiências, apenas as repetem. Dessa forma, os seres humanos possuem a conscientização em relação às ações empreendidas perante a vida. Os animais, ao contrário, são condicionados pela espécie à qual pertencem. 
Somos humanos porque somos "aprendentes". Os animais pertencem ao primado do condicionamento genético, da instrução, do treinamento, do adestramento, e esses são os limites do seu aprendizado. Nós, os humanos, somes seres disso tudo também. Mas, para "além disso", somos seres de algo bem mais complexo. Algo que ao longo da história foi recebendo nomes como educação, capacitação, formação humana. Afinal, os animais sabem e sentem. E nós sabemos e sentimos. Mas a diferença está em que nós sabemos que sabemos e nós sabemos sabendo (ou não sabendo); e nós sentimos sabendo e nós sabemos sentindo. (BRANDÃO, 1986, p. 12).

Refletindo sobre a realidade social do momento presente, em que a humanidade está imersa, verifica-se que, apesar da luta das organizações sociais, escolas e governos de matiz popular em favor da interculturalidade, há uma imposição, por parte do sistema dominante hegemônico, assentada na lógica monocultural.

Segundo Vieytez (2011), essa lógica é veiculada por meio de resoluções de organismos internacionais, planos de governos, declarações dos parlamentos e outros documentos similares que, aparentemente, enfatizam um discurso politicamente correto a favor da diversidade cultural como algo positivo pelo fato de que essa diversidade proporcionaria uma maior riqueza de aprendizagens de saberes em virtude do contato de pessoas de distintas culturas.

Por outro lado, esse discurso insiste, de modo contraditório, que é necessário garantir a coesão e a integração social das sociedades em relação à valoração dos bens culturais comuns a essas sociedades, impondo, desse modo, a pretendida uniformidade cultural. Com efeito, esse discurso acaba provocando a imposição de uma padronização cultural em benefício das culturas dominantes, já que - na prática - a ideia da coesão social anula e desrespeita a diversidade cultural dos povos minoritários, pois essa coesão leva ao assimilacionismo cultural, o qual parte do pressuposto de que:

A integração das pessoas imigrantes (ou das pertencentes a grupos minoritários tradicionais) na sociedade supõe a necessidade de operar uma mudança ou substituição cultural e identitária. Desde o assimilacionismo se entende 
que no processo integrador é preciso o abandono dos elementos culturais e referenciais minoritários para aceitar os majoritários, de onde parece inferir-se que não é possível a dupla filiação de identidade ao menos no espaço público. (VIEYTEZ, 201 1, p. 109).

Também pode ocorrer, associado ao assimilacionismo, segundo Vieytez (2011), o processo de diferencialismo cultural, que restringe ainda mais a participação das comunidades minoritárias (imigradas ou não) nas comunidades pertencentes às culturas dominantes e vice-versa.

A imposição da uniformidade cultural ocorre e é sustentada, conforme Althusser (1985), por meio da força dos aspectos econômicos e dos aspectos vinculados à ideologia que orientam o sistema capitalista. Isto acontece por meio da reprodução dos modos de agir e de pensar das classes dirigentes hegemônicas. Quanto a isso, na visão de Guattari e Rolnik (2000), no sistema econômico de lógica capitalista, o seu poder não se reduz apenas à apropriação da mais-valia econômica, mas à apropriação do próprio modo de ser das pessoas com o objetivo de viabilizar, social e politicamente, a ordem dominante. Essa reprodução se perpetua nos tempos históricos, por intermédio da persuasão e da violência empregadas pelas classes dominantes às classes subalternas, pela ingerência dos processos político-pedagógicos responsáveis pela manutenção do status quo, que acontecem via aparelhos repressores de estado (forças armadas e o judiciário) e via aparelhos ideológicos de estado (meios de comunicação, família, escola e religião).

Em decorrência dessa reprodução, as classes hegemônicas oprimem as classes subalternas fazendo com que estas adquiram os hábitos e as manifestações culturais daquelas. Isso ocorre mediante ações caracterizadas pela não dialogicidade. Nos espaços escolares, em sua maioria, segundo Bourdieu e Passeron (1975), é reproduzida a cultura da classe dominante, em detrimento da cultura das classes subalternas, por meio da violência simbólica, que ocorre por intermédio da ação pedagógica, que inculca e impõe às pessoas, de forma sutil, o discurso das classes de maior poder. Assim: 
A ação pedagógica reproduz o arbitrário cultural das classes dominantes ou dominadas. A ação pedagógica (institucionalizada) da escola reproduz a cultura dominante e, através dessa, a estrutura de relações de força dentro de uma formação social, possuindo o sistema educativo dominante o monopólio da violência simbólica. (STOER, 2008, p. 15).

Logo, a escola comunica - de maneira hegemônica - os valores e hábitos da cultura dessas classes em prejuízo de uma visão intercultural do mundo, ou seja, a escola não enxerga a realidade sob o prisma da diversidade cultural, como bem lembra a metáfora de Santos (2005): "o mundo é um arcoíris de culturas."

Ora partindo desse conceito para uma (eventualmente e arriscada) analogia e admitindo que é importante ser capaz de "ver" este e outros conjuntos de cores, poderemos recordar que algumas pessoas, apesar de disporem de um aparelho visual morfologicamente bem constituído, não são capazes de discernir uma gama de tonalidade de cores que compõem o arco-íris. Alguns ficam com uma reduzida capacidade de identificação de tons cinzentos: são os daltônicos. A analogia proposta aqui é a de que a não conscientização da diversidade cultural que nos rodeia em múltiplas situações constituiria uma espécie de daltonismo cultural. (CORTESÃO; STOER, 1996, p. 38).

De modo efetivo, surgem movimentos alternativos a esse modelo de educação monocultural "daltônica", propondo um modelo intercultural que possibilite, em conjunto a outros campos de atuação dos seres humanos, a edificação de outro mundo, forjado numa racionalidade plural, baseada na complementaridade dos saberes de todas as culturas existentes no mundo.

Essa racionalidade se efetiva e efetivará mediante processos que culminem em ações que possibilitem $\circ$ fortalecimento das comunidades de aprendizagens na construção de projetos políticos e pedagógicos que abarquem a diversidade cultural do local em comunicação com o nacional e o global. Na direção da construção dessa racionalidade, Santos (2005) aponta para uma outra globalização, isto é, 
para uma globalização alternativa ao criticar o monoculturalismo do saber e da razão indolente, através da inteligibilidade dos movimentos sociais e da ecologia dos saberes. Enfatizando a territorialidade cultural do sul do mundo no sentido da constituição de outra temporalidade e da dilatação do presente, o que aprofunda as análises de longa duração. (BARBOSA, 2005, p. 9).

A construção dessa ecologia de saberes poderá se realizar por intermédio de ações pedagógicas, consignadas sob a égide da integração da educação e da cultura popular, da educação e da cultura da ciência, elaboradas no território do Sul global e em alguns lugares do Norte global (que se opõem ao modelo cultural hegemônico). Nesse sentido, a ecologia dos saberes apregoa que nenhuma cultura pode se considerar superior a outra. Decorre daí que os saberes de determinada cultura não devem encobrir os saberes produzidos por outras culturas, mas, sim, atuarem de forma dialógica pelo encontro entre esses saberes - de natureza popular e científica - visando à instalação de uma existência vivida sob o signo da igualdade na diferença.

Essa igualdade pressupõe que as diferenças sejam algo que potencializa e possibilita o desenvolvimento mais harmônico e solidário, isto é, o diferente deve ser tratado em igualdade de condições e oportunidades do ponto de vista social, político e cultural. Portanto, a igualdade deve ser construída na diversidade e na complementaridade de culturas.

Na diversidade residem as possibilidades do progresso da humanidade - uma vez que o progresso deriva da colaboração entre culturas diferentes, e porque através da diversidade torna-se possível a compreensão das culturas - na medida que só a compreensão das diferenças enquanto sistema permitirá atribuir a qualquer cultura o seu sentido verdadeiro. (ROWLAND, 1987, p. 8-9).

Essa compreensão das diferenças pode ser alcançada mediante ações baseadas no interculturalismo crítico, o qual se fundamenta em uma epistemologia e em uma política que vislumbram a (re)construção de uma utopia concreta sustentada pela polifonia cultural, que se constitui por um agir 
diário, impregnado de amizade e amor, entre as pessoas de todo o mundo, em substituição à guerra imposta pela colonialidade e o colonialismo. Isto é, em razão de uma vida, cujo objetivo primeiro seja a paz.

\begin{abstract}
A paz não pode identificar-se, pois com o fim dos combates que acabam sem combatentes, pelo fracasso de uns e a vitória dos outros, quer dizer, com os cemitérios ou os impérios universais futuros. A paz deve ser minha paz, uma relação que parte de um eu e vá para o outro, no desejo e na bondade, onde o eu, por sua vez, se mantém e existe sem egoísmo. (LEVINAS, 1977, p. 310).
\end{abstract}

Nesse sentido, esse processo de paz pode ser concretizado por uma educação intercultural que desconstrua o caráter monocultural e etnocêntrico hegemônico e que, de maneira concomitante, desenvolva projetos e atividades que promovam e integrem os valores culturais e os saberes populares que os alunos trazem das experiências de suas comunidades com os saberes e os valores culturais da escola numa perspectiva do respeito à diversidade desses valores e saberes, com vistas à emersão de comunidades centradas na justiça e na solidariedade cognitiva, social, política e cultural (FREIRE, 1996; CANDAU, 2013).

Isto é, que o mundo seja erigido com base no interculturalismo crítico baseado nos seguintes preceitos e características:

Um processo dinâmico e permanente de relação, comunicação e aprendizagem entre culturas em condições de respeito, legitimidade, simetria e igualdade.

Um intercâmbio que se constrói entre pessoas, conhecimentos, saberes e práticas culturalmente diferentes, buscando desenvolver um novo sentido entre elas na sua diferença.

Um espaço de negociação e de tradução onde as desigualdades sociais, econômicas e políticas, e as relações e os conflitos de poder não são mantidos ocultos e sim reconhecidos e confrontados.

Uma tarefa social e política que interpela ao conjunto da sociedade, que parte de práticas e ações sociais concretas e conscientes e tenta criar modos de responsabilidade e solidariedade.

Uma meta a alcançar. (WALSH, 2001, p. 10-11). 
Seguindo essa senda sugerida por Walsh (2001), a educação popular pode contribuir enormemente para atingirmos essa meta de uma educação como prática de uma interculturalidade. A educação popular, sob a ótica do pensamento freireano, sempre teve a preocupação de denunciar as injustiças praticadas contra os oprimidos e, a partir dessa denúncia, conjugou a teoria e a prática em prol do anúncio e da consecução de um viver centrado em uma política e em uma pedagogia voltada para a libertação de todos os seres humanos.

Essa pedagogia tem seu núcleo no diálogo entre seres humanos como sujeitos históricos, sociais e culturais, constituídos a partir da complementaridade da diversidade cultural, tendo como fundamento o respeito à preservação da identidade cultural. A pedagogia da educação popular tem como ponto de partida e de chegada a utopia concreta de um mundo engendrado na participação, no amor, na solidariedade e na justiça social, (re)criada na luta cotidiana de educandos e educadores, comprometidos com a transformação de uma realidade de opressão, dominada pela ética do mercado, para uma realidade ancorada na liberdade e na democratização social e política, nos mais diversos lugares da sociedade, cujo fundamento primeiro seja a ética em favor da humanização plena.

Os educadores populares assumem esta como uma concepção educativa que tem suas práticas, conceitualizações, pedagogias e metodologias, mediante as quais fazem vigente sua proposta de indignação ética frente ao capitalismo atual e fazem uma proposta de emancipação e de transformação desta sociedade para construir uma mais humana e justa a partir dos processos educativos, mediante os quais realizam seu trabalho na sociedade. (MEJíA, 2012, p. 64).

Logo, a educação popular traz em seu âmago a luta cotidiana de coletivos de educadores, de movimentos sociais e do povo oprimido em favor de dias melhores, pautados pela construção de um sistema social em que todas as pessoas caibam. Nesse caminho, Torres (2007) aponta que, sobretudo 
na América Latina, a educação popular teve e tem como agenda a prática da denúncia da lógica capitalística excludente, concomitantemente com a enunciação e a realização de práticas sociais e culturais, cujo fazer políticopedagógico tem como marco a assunção dos seres humanos como sujeitos do seu devir histórico e que lutam pela transformação social.

Esse fazer político-pedagógico acontece num processo de ação e reflexão sobre as condições e as realidades do povo oprimido, em que os educadores e os intelectuais vão ao encontro desse povo para, em diálogo, desvelar a situação de opressão em que eles vivem e a partir dessa situação, por meio de uma educação dialógica, construir uma vida decente, a partir da conscientização e da participação mútua, conforme o seguinte parecer:

$\bigcirc$ projeto educativo revolucionário proposto por Paulo Freire se inscreve em reação contra a educação bancária que não considera suficientemente o papel participativo do homem ou da mulher na construção do mundo. $\bigcirc$ homem sujeito de sua história, dialogando com seus parceiros humanos, é capaz de atingir um nível de consciência crítica que lhe permita de transformar a sociedade circundante. (MORIN, 2004, p. 76).

Esse projeto divulgado e praticado por Paulo Freire foi e continua sendo reinventado, nos mais diversos lugares das sociedades, por meio de experiências que subvertem a ordem política, social e cultural estabelecida pelo status quo, aportadas por uma teoria pedagógica plural que faz emergir práticas e saberes eclipsados.

Essa teoria, que é reafirmada pelo pilar da descolonização, conforme lembra Mignolo (2005), é uma síntese teórica entre a tradição da Ciência e da Filosofia ocidental e a variedade de conhecimentos encobertos pelo véu do ocidentalismo e do eurocentrismo. De acordo com Streck (2005), essa teoria "se dá a partir da inserção da matriz formulada pelas ausências e emergências. Pelos saberes pedagógicos encobertos ou silenciados e pelas vozes que surgem como sobrevivência, resistências e como desejo e reinvenção de possibilidades de vida." $\bigcirc$ silenciamento dos povos dominados decorre, em grande parte, do domínio epistêmico e político produzido pelos países que detêm a hegemonia 
da geopolítica mundial (países do Norte global), imposta aos países do Sul global por intermédio da invasão cultural.

Por outro lado, é imprescindível que, em vez da invasão cultural, seja implementada a interação entre as culturas, motivada e realizada pela acolhida e respeito à alteridade de todos os povos. Nesse sentido, a Pedagogia de Paulo Freire - pelo seu caráter utópico, crítico e dialógico - pode ajudar no surgimento de um interculturalismo crítico, ou seja, conforme Dussel (2012), por ser uma Pedagogia que enfatiza a importância do ser humano em escala planetária e que promulga uma ética em defesa da vida de todos os povos do mundo.

\section{PAULO FREIRE E A INTERCULTURALIDADE CRÍTICA}

Em muitos de seus livros Paulo Freire aborda o tema da interculturalidade crítica ao pregar e ao defender a construção de um mundo mais humano e solidário, fundado na intersubjetividade crítica, em favor da vocação ontológica e histórica dos seres humanos, do ser mais com os outros, em meio à pluralidade cultural destes.

No livro Pedagogia da autonomia, Freire enfatiza a importância que os docentes devem imprimir nas suas práticas pedagógicas em relação ao ensinar com base no reconhecimento à identidade cultural deles como docentes, tendo o cuidado de não ferir a identidade cultural dos alunos. Freire (1996, p. 41)

escreve que "A assunção de nós mesmos não significa a exclusão dos outros. É a 'outredade' do 'não eu', ou do tu, que me faz assumir a radicalidade do meu eu."

Um dos assuntos que Freire escreve com persistência nos seus livros é o problema da violência praticada pelos opressores aos oprimidos, no que diz respeito a como se elabora o processo de esmagamento da cultura desses oprimidos por esses opressores e de como esse esmagamento é prejudicial para a efetivação do diálogo intercultural que visa à humanização de todos os seres humanos, já que esse processo invade, domina e destrói a cultura dos subalternos (os oprimidos). 
Uma das características fundamentais do processo de dominação colonialista ou de classe, sexo, tudo misturado, é a necessidade que o dominador tem de invadir culturalmente o dominado. Portanto, a invasão cultural é fundamental porque ela pensa no poder, ora através de métodos violentos, táticos, ora através de métodos cavilosos. $\bigcirc$ que a invasão cultural se pretende, entre outras coisas, é exatamente a destruição, o que felizmente não consegue em termos concretos. É fundamental ao dominador: triturar a identidade cultural do dominado. (FREIRE, 2004, p. 14).

○ tema da invasão cultural é evidenciado também no livro Ação cultural para a liberdade, no qual Freire faz uma denúncia veemente contra os abusos praticados pelas nações "metropolitanas" contra os países do chamado terceiro mundo, no que concerne à imposição da cultura dessas nações a esses países como sendo a mais avançada. Assim, esse autor relata:

Daí que o subdesenvolvimento apareça para muitos teóricos metropolitanos como expressão de atraso, de incapacidade. $\bigcirc$ Terceiro Mundo, como um mundo "marginal" - uma espécie de favela maior - sem nenhuma viabilidade histórica própria e cuja "salvação" por isso mesmo se encontra em seguir, docilmente, os modelos estabelecidos de fora. Modelos de sociedades metropolitanas, no fundo, modelos das classes dominantes destas sociedades. Os interesses expansionistas destas classes, aos quais se atrelam os das classes dominantes das sociedades dependentes Primeiro Mundo do Terceiro - estão implícitos nestas noções. (FREIRE, 1981, p. 18).

Já no livro Pedagogia da esperança, Freire relata sobre a relevância do papel da luta pela construção de uma sociedade com base no princípio da vivência da unidade na diversidade para que aconteça a emersão do pluralismo cultural.

É preciso também deixar claro que a sociedade a cujo espaço por motivos econômicos, sociais, históricos, chegaram outros grupos étnicos e aí se inseriram em relação subordinada, tem sua classe dominante, sua cultura de classe, sua linguagem, sua sintaxe, sua semântica de classe, seus gostos, seus sonhos, seus fins, seus projetos, 
valores, programas históricos. Sonhos, projetos, valores, linguagem que a classe dominante não apenas defende como seus e, sendo seus, diz serem nacionais, como exemplares, mas também por isso mesmo, "oferece" aos demais através de n caminhos, entre eles, a escola e não aceita recusa. É por isso que não há verdadeiro bilinguismo, muito menos multilinguismo, fora da multiculturalidade e não há esta como fenômeno espontâneo, mas criado, produzido politicamente, trabalhado, a duras penas, na história. Daí, mais uma vez, a necessidade da invenção da unidade na diversidade. (FREIRE, 1992, p. 156-157).

O tema da colonialidade de gênero é debatido por Freire no livro Pedagogia da esperança, em que ele atende as sugestões das feministas norte-americanas, as quais reclamaram que esse autor não inclui a palavra mulher, no livro Pedagogia do oprimido, quando se referia aos seres humanos. Em produções de livros subsequentes, Freire introduz as palavras homens e mulheres para designar a humanidade como um todo, pois reconhece o quão é ideológica e androcêntrica a linguagem ao expressar falas que não incluem as diferenças de gênero. Para Freire (1992, p. 68): "a discriminação da mulher expressada e feita pelo discurso machista e encarnada em práticas concretas é uma forma colonial de tratá-la, incompatível, portanto, com qualquer posição progressista de mulher ou de homem, pouco importa."

Já o tema do colonialismo do ser e do poder aparece na passagem a seguir:

A presença predatória do colonizador, seu incontido gosto de sobrepor-se, não apenas ao espaço físico, mas ao histórico e cultural dos invadidos, seu mandonismo, seu poder avassalador sobre as terras e gentes, sua incontida ambição de destruir a identidade cultural dos nacionais, considerados inferiores, quase bichos, nada disso pode ser esquecido quando, distanciados no tempo, corremos o risco de "amaciar" a invasão e vê-la como uma espécie de presente "civilizatório" do chamado Velho Mundo. Minha posição hoje, decorridos 500 anos da conquista, não sendo a de quem se deixe possuir pelo ódio aos europeus, é a de quem não se acomoda diante da malvadez intrínseca a qualquer forma de colonialismo, de invasão, de espoliação. É a de quem recusa encontrar positividades em um processo por natureza perverso. (FREIRE, 2000, p. 73-74). 
A temática da assunção da língua materna pelos povos libertados do jugo político do colonizador é abordada por Freire em Cartas a Guiné-Bissau como um dos fundamentos imprescindíveis para a construção de processos políticos e pedagógicos capazes de produzir uma educação intercultural crítica com vistas à mudança social.

A imposição da língua do colonizador ao colonizado é uma condição fundamental para a dominação colonial que se estende na dominação neocolonial. Não é por acaso que os colonizados falam da sua língua como língua e da língua do colonizado como dialetos; da superioridade e riqueza da primeira a que contrapõe a "pobreza" e a "inferioridade" da segunda. [...] Na verdade, o processo de libertação de um povo não se dá em termos profundos e autênticos, se esse povo não reconquista a palavra, o direito de dizê-la de "pronunciar" e de "nomear" o mundo. (FREIRE, 1978, p. 145).

Cinco adolescentes mataram hoje, barbaramente, um índio pataxó, que dormia tranquilo, numa estação de ônibus em Brasília. Disseram à polícia que estavam brincando. Que coisa estranha. Brincando de matar. Tocaram fogo no corpo do índio como quem queima uma inutilidade. Um trapo imprestável. Para sua crueldade e seu gosto de morte, o índio não era um tu ou um ele. Era aquilo, aquela coisa ali. Uma espécie de sombra inferior no mundo. Inferior e incômoda, incômoda e ofensiva. [...] Que coisa estranha, brincar de matar índio, de matar gente. Fico a pensar aqui, mergulhado no abismo de uma profunda perplexidade, espantado diante da perversidade intolerável desses moços desgentificando-se, no ambiente em que decresceram em vez de crescer. [...] Se a nossa opção é progressista, se estamos a favor da vida e não da morte, da equidade e não da injustiça, do direito e não do arbítrio, da convivência com o diferente e não de sua negação, não temos outro caminho senão viver plenamente a nossa 
opção. Encarná-la, diminuindo assim a distância entre o que fizemos e o que fazemos. Desrespeitando os fracos, enganando os incautos, ofendendo a vida, explorando os outros, discriminando o índio, o negro, a mulher, não estarei ajudando meus filhos a ser sérios, justos e amorosos da vida e dos outros [...] (FREIRE, 2000, p. 64-67).

Diante desse manifesto emitido por Paulo Freire, cabe a nós, educadores - em solidariedade aos nossos educandos -, anunciar e praticar ações impregnadas de valores fundados numa ética em prol de toda a comunidade da vida em que a diversidade cultural e a justiça social sejam os pilares fundamentais para a construção de um mundo diferente pautado por uma educação como prática de cooperação.

\section{CONSIDERAÇÕES FINAIS}

Ao longo da obra de Paulo Freire, são encontradas várias referências acerca do tema da interculturalidade crítica. Mesmo sem aparecer explicitamente o termo interculturalidade crítica em seus trabalhos, Freire aponta de maneira enfática - nos seus escritos - características de um fazer e de um pensamento político-pedagógico voltado à emersão da educação intercultural crítica. Como exemplos dessas características em suas obras, podemos elencar: o respeito e o acolhimento às diversas culturas, o diálogo entre os saberes, a denúncia do imperialismo, a educação como prática de liberdade, o respeito à alteridade e a denúncia à opressão concomitantemente ao anúncio de um fazer políticopedagógico forjado na construção da igualdade em meio à diversidade. Enfim, a perspectiva apontada por Freire sinaliza um conviver criado e recriado mediante procedimentos epistemológicos, políticos e éticos forjado na ideia do ser mais com o outro ancorado em uma política e em uma pedagogia fundada numa ação cultural para a libertação.

Dessa forma, Freire confere importância às relações interculturais, ancorada na radicalidade do diálogo e na radicalidade ética, em favor de um mundo em que seja possível construir a paz e a justiça social. $\bigcirc$ autor acentua 
o diálogo com base na igualdade entre as pessoas em meio às suas diferenças. Portanto, consideramos que o pensamento de Paulo Freire é de grande relevância para que, em diálogo com outros pensamentos - como é o caso dos ideários de Dussel, Mounier, Santos, Levinas, Walsh, Mignolo, Quijano, Torres, Walsh, Memmi e Fanon -, ajude na efetivação da utopia concreta da educação intercultural crítica.

Freire divulgou e praticou durante toda a sua vida um testemunho em favor da humanização plena - com base na vocação ontológica da humanização do ser em oposição ao ter em comunhão com os outros, respeitando as diferenças destes, no que se refere aos aspectos ligados às dimensões de gênero, etnia, sexo, nacionalidade, língua, religião e classe social.

Esse testemunho e seus ideais continuam a ser proclamados também pelos autores citados, por intelectuais, educadores e educandos, em todo o mundo, por meio da denúncia do colonialismo e da colonialidade do ser, dos saberes e do poder e, mediante essa denúncia, promovem o anúncio e já praticam, apesar de ser em pequena escala, uma civilização fundada na reciprocidade com base na educação como prática da solidariedade, da cooperação e do amor em meio à diversidade cultural.

Por fim, como palavras finais, diríamos que diante da intolerância crescente no mundo da vida, no que se refere à não aceitação do diferente ao padrão hegemônico eurocêntrico, como é o caso da rejeição recente dos refugiados sírios na Europa, é de extrema urgência que se aprofunde a implementação de currículos interculturais, mediante a formação continuada de professores e de educandos, aportada em práticas geradoras da integração cultural em meio às diferenças de classe, etnia, sexo, gênero, nacionalidade e religião. E para que esses currículos sejam implantados no cotidiano das escolas e demais organizações sociais, é essencial que a educação popular de Paulo Freire esteja na ordem do dia, ou seja, que a utopia e a ética freireana sempre sejam uma inspiração para as ações político-pedagógicas de educandos, educadores e demais atores sociais, tendo-a como método visando à construção de uma interculturalidade crítica. 
A educação escolar envolve aspectos importantes da vida de um ser humano, como a produção de conhecimentos e de comportamentos sociais. Conhecimentos e comportamentos entrelaçam-se na vida das pessoas por meio do cotidiano escolar, produzindo os fundamentos de uma sociedade. No sentido mais geral, podemos aceitar a ideia de que uma sociedade resulta das diferentes relações que pessoas e grupos sociais estabelecem entre si, constituindo o seu mundo. Essa compreensão de educação e escola, certamente pode se constituir em possibilidades de agência humana nesse processo de construção e reconstrução do mundo, mediante um diálogo intercultural de seus sujeitos.

O pensamento pedagógico de Paulo Freire, tendo como referência esse diálogo, em meio a um mundo sempre mais tensionado por suas contradições, constitui fonte de reflexão à abertura de sendas possíveis para a instauração de uma interculturalidade crítica como base na convivialidade dos seres humanos, cujo núcleo central seja os valores do amor, da sensibilidade e da compaixão por toda a comunidade da vida. Enfim, em nossa visão, diante desse quadro político, econômico e social de acentuada desumanização, o diálogo das vertentes da interculturalidade crítica e da educação popular pode contribuir em muito para a emancipação de educandos e educadores em virtude do fato de que são vertentes que lutam em favor de uma sociedade em que todas as pessoas caibam, em oposição à educação apoiada na lógica do capital, praticada no Brasil e em outras partes do mundo de maneira hegemônica, que valoriza em primeiro lugar o dinheiro em detrimento das populações mais pobres.

Assim, compreendemos que o diálogo empreendido neste artigo é de grande relevância por suscitar temas, de certa forma, "marginais" na formação de futuros professores em nossas instituições de ensino e também por - quem sabe - provocar novos diálogos a respeito desses temas nas pessoas que se ocupam do campo da educação.

\section{REFERÊNCIAS}


ALTHUSSER, L. Aparelhos ideológicos de Estado. Rio de Janeiro: Graal, 1985.

ANDREOLA, B. A. Do preconceito de Hegel ao diálogo das civilizações. In: Educação, cultura e resistência: uma abordagem terceiro mundista. Santa Maria: Palotti/ITEPA/EST, 2002.

\section{BARBOSA, W. A. Cultura puri e Educação Popular em Araponga/MG:} duzentos anos de solidão em defesa da vida e do meio ambiente. 2005. Tese (Doutorado em Educação)-Universidade Federal de Santa Catarina, Florianópolis, 2005.

BOFF, L. Saber cuidar: ética do humano - compaixão pela terra. Petropólis: Vozes, 2000.

BOURDIEU, P.; PASSERON, J. A reprodução. Elementos para uma teoria do sistema de ensino. Rio de Janeiro: Francisco Alves, 1975.

BUBER, M. Eu e Tu. São Paulo: Centauro, 2001.

BUCCI, E.; KEHL, M. R. Videologias: ensaios sobre televisão. São Paulo: Boitempo, 2004.

BRANDÃO, C. R. Identidade e etnia-construção da pessoa e resistência cultural. São Paulo: Brasiliense, 1986.

CANDAU, V. M. F. Educación Intercultural Crítica: construyendo caminos. In: WALSH, C. (Org.) . Pedagogías decoloniales: prácticas insurgentes de resistir (re)existir y (re)vivir. Quito: Ediciones Abya - Yala, 2013.

CASTRO-GÓMEZ, S. Ciências sociais, violência epistêmica e o problema da "invenção do outro". In: LANDER, E. (Org.). A colonialidade do saber: eurocentrismo e ciências sociais, perspectivas latino-americanas. Buenos Aires: CLACSO, 2005. p. 169-186.

CORTESÃO, L.; STOER, S. A interculturalidade e a educação escolar: dispositivos pedagógicos e a construção de ponte entre as culturas. Revista de Inovação Educacional da Universidade do Porto, Porto, v. 9, n. 1, 1996.

DUSSEL, E. 1492: o encobrimento do outro: a origem do mito da modernidade: Conferências de Frankfurt. Petrópolis: Vozes, 1993.

DUSSEL, E. Ética da libertação na idade da globalização e exclusão. Petrópolis: Vozes, 2012. 
FANON, F. Os condenados da terra. Rio de Janeiro: Civilização Brasileira, 1968.

FREIRE, P. Ação cultural para a liberdade e outros escritos. Rio de Janeiro: Paz e Terra, 1981.

FREIRE, P. Cartas a Guiné-Bissau: registros de uma experiência em processo. Rio de Janeiro: Paz e Terra, 1978.

FREIRE, P. Pedagogia da autonomia: saberes necessários à prática educativa. São Paulo: Paz e Terra, 1996.

FREIRE, P. Pedagogia da esperança. Rio de Janeiro: Paz e Terra, 1992.

FREIRE, P. Pedagogia da indignação: cartas pedagógicas e outros escritos. São Paulo: Ed. Unesp, 2000.

FREIRE, P. Pedagogia do oprimido. Rio de Janeiro: Paz e Terra, 2005.

FREIRE, P. Pedagogia da tolerância. São Paulo: Ed. Unesp, 2004.

GUATTARI, F; ROLNIK, S. Micropolítica. Cartografias do Desejo. 6. ed. Petrópolis: Vozes, 2000.

HUBERMAN, L. História da riqueza do homem. Rio de Janeiro: Zahar Editores, 1982.

LEVINAS, E. Totalidad e infinito. Salamanca: Sigueme, 1977.

MARQUES, M. O. Escrever é preciso: o princípio da pesquisa. Ijuí: Unijui, 1998.

MEJÍA, M. R. Educação e pedagogias críticas a partir do Sul: cartografias da educação popular. Rio de Janeiro: Novamerica, 2012.

MEMMI, A. Retrato do colonizado precedido do colonizador. Rio de Janeiro: Paz e Terra, 1977.

MIGNOLO, W. A colonialidade de cabo a rabo: o hemisfério ocidental no horizonte conceitual da modernidade. In: LANDER, E. (Org.). Colonialidad del saber America Latina e Ciencias Sociales. Perspectivas Latino-americanas. Buenos Aires: CLACSO, 2005.

MORIN, A. Pesquisa-ação integral e sistêmica: uma antropopedagogia renovada. Rio de Janeiro: DP\&A, 2004. 
MOUNIER, E. O personalismo. São Paulo: Centauro, 2004.

OLIVEIRA, L. F.; CANDAU, V. M. F. Pedagogia Decolonial e Educação antirracista no Brasil. Educação em Revista, Belo Horizonte, v, 26, n. 1, abr. 2010.

QUIJANO, A. Colonialidad del poder y clasificación social. In: CASTRO-GÓMEZ, S.; GROSFOGUEL, R. (Org.). El giro decolonial: reflexiones para una diversidad epistémica más Allá del capitalismo global. Bogotá: Siglo del Hombre Editores, 2007.

ROWLAND, R. Antropologia, História e diferença. Porto: Afrontamento, 1987.

SANTOS, B. S. Descolonizar el saber, reinventar el poder. Montevideo: Ediciones Trilce, 2010.

SANTOS, B. S. O Fórum Social Mundial: Manual de Uso. Porto: Afrontamento, 2005.

SEVERINO, A. J. Humanismo, Personalismo e os desafios sociais da educação contemporânea. Revista de Educação Pública, Cuiabá, v. 18, n. 36, p. 155-163, jan./abr. 2009. Disponível em: < http://periodicoscientificos.ufmt.br/ ojs/index.php/educacaopublica/article/view/528/449>. Acesso em: 02 out. 2017.

STOER, S. A genética cultural da reprodução. Educação, Sociedade \& Culturas, n. 26, p. 85-90, 2008.

STRECK, D. R. Encobrimentos e Emergências Pedagógicas na América Latina. Revista Lusófona de Educação, Lisboa, n. 6, p. 55-66, 2005.

TORRES, A. La educación popular: trayectoria y actualidad. Bogotá: El Búho, 2007.

TORRES, N. M. Sobre la colonialidad del ser: contribuciones al desarrollo del concepto. In: CASTRO-GÓMEZ, S.; GROSFOGUEL, R. (Org.). El giro decolonial: reflexiones para una diversidad epistémica más Allá del capitalismo global. Bogotá: Siglo del Hombre Editores, 2007.

VYEITEZ, E. J. R. Juntos pero no revueltos: sobre diversidad cultural, democracia y derechos humanos. Madrid: Maya Ediciones, 2011.

WALLERSTEIN, I. M. O universalismo europeu: a retórica do poder. São Paulo: Boitempo, 2007. 
WALSH, C. La Educación Intercultural em La Educación. Lima: Ministerio de Educación, 2001.

Recebido em:: 21 de outubro de 2017 Aceito em:: 21 de junho de 2018

Endereço para correspondência: Rodovia SC 283, Km 8, Fragosos, 89700000, Concórdia, Santa Catarina, Brasil; jose.figueiredo@ifc.edu.br 
